\title{
JUSTIÇA RESTAURATIVA E MEDIAÇÃO PENAL
}

Muriele Freitas Duarte, Sarah Aparecida Oliveira dos Santos, Pablo Rodrigo França

Universidade do Oeste Paulista - UNOESTE, curso de Direito, Presidente Prudente, SP.

\section{RESUMO}

O presente trabalho busca ilustrar sobre a Mediação sob o âmbito do Direito Processual Penal, de forma que o assunto tratado vem se tornando presente na área criminal como um novo método de resolução de conflitos. Diante disso, notamos a necessidade de tal e matéria criminal, obtendo se assim, uma melhor forma de resolução de conflitos, em conformidade com os princípios e normas jurídicas. A justiça restaurativa aparece como uma resposta a necessidade presente no meio judiciário. Apesar de não haver uma legislação específica sobre o assunto a ser tratado, alguns institutos permitem a utilização da Mediação Penal no ordenamento jurídico brasileiro. 0 uso desse meio alternativo de resolução de conflitos pode ser percebido diante da criação de alguns projetos, conforme exposto neste trabalho.

Palavras-chave: Mediação. Justiça Restaurativa. Conflitos. Direito Processual Penal. Área Criminal.

\section{RESTORATIVE JUSTICE AND CRIMINAL MEDIATION}

\begin{abstract}
The presente work seek to ilustrate about Mediation under the scop of Criminal Procedural Law, so that the subject matter is becoming present in the criminal area as new method of conflict resolution. In view of this, we note the need for such an implementation of this new alternative mechanism in the juridical environment when dealing with criminal matters, thus obtaining a bater way of resolving conflicts, in accordance with legal principles and norms. Restorative justice appears as a response to the presente need in the judiciary. Although there is no specific legislation on the subject to be trated, some institutes allow the use of Criminal Mediation in the Brazilian legal system. The use of this alternative means of conflict resolution can be perceived in the creation of some projects, as explained in this work.
\end{abstract}

Keywords: Mediation. Restorative Justice. Conflicts. Criminal Procedural Law.Criminal Area.

\section{INTRODUÇÃO}

O presente projeto de pesquisa estudará a dogmática do tema "MEDIAÇÃO, NO CÓDIGO DE PROCESSO PENAL, visto que está se tornando uma nova técnica dentre o meio do Direito Penal.

Em face do aumento da criminalização, o judiciário se preocupou em utilizar métodos simplificados para resolver tais conflitos dessa forma evitando a crise no Poder Judiciário, sendo assim escolhida a mediação.

A mediação Penal é uma técnica alternativa, onde uma terceira pessoa, o mediador, cujo é totalmente imparcial conduz o processo.

Contudo, será que a Justiça Restaurativa é vista realmente como método eficaz no meio do Direito Penal? 
A problemática em que o projeto de pesquisa aponta, justifica-se em como utilizar a mediação como solução para os problemas enfrentados em face a administração pública, principalmente em relação aos Tribunais, respaldando a finalidade do acesso à justiça.

O propósito da mediação para resolução de conflitos e tem como principal objetivo caso de relações continuadas, questões familiares, condomínios, vizinhos, colegas de trabalho, infância e juventude e relações em que haja afeto entre as partes, pois dessa forma permite a preservação do vínculo ao tratar o conflito como parte do histórico das partes e não como um fenômeno isolado, ampliando o autoconhecimento de todos e envolvendo-os na solução do litígio.

O presente projeto de pesquisa pretende esclarecer e revelar o conceito de Mediação, abordando as principais vantagens em se adotar determinado método proposto do Código de Processo Penal.

\section{METODOLOGIA}

A pesquisa desenvolvida tem como objetivo analisar, e verificar o assunto tratado, buscando assim indicar as vantagens de se utilizar o método da mediação no Direito Processual Penal, e como a mesma é vista e aplicada. Dessa forma pesquisamos com base em artigos e textos presentes na Internet, e por meio das informações idealizamos nossa versão sobre o tema tratado.

\section{RESULTADO}

O artigo percepcionado, até o presente momento, na Justiça Restaurativa e Mediação Penal, obteve resultado dentro dos parâmetros legais, um método eficaz na resolução de conflitos criminais simples, que possibilitou que houvesse uma diminuição nas reincidências, e que os envolvidos pudessem restaurar suas relações.

A mediação tem com seu objetivo investigar o conflito de forma geral, e escutar as partes, e assim visa reprimir e do delituoso de fato, e não o conflito.

Logo, o uso da mediação vem mostrando a cada dia, que pode se utilizar como uma forma de resolução de conflitos, sem que haja uma lotação, no sistema carcerário, pois o mesmo já vem sofrendo com o problema de superlotação. A mediação resolve os problemas de menor intensidade em relação a gravidade, deixando assim o sistema carcerário para casos mais gravosos, os quais devem ser resolvidos com uma pena restritiva de liberdade.

\section{DISCUSSÃO}

Ao argumentar sobre mediação, encontramos a figura do mediador, tendo o papel nessa relação intermediário. A princípio devemos saber distinguir a figura do mediador do conciliador, o que difere o conciliador do mediador é a autoridade de conduzir e não de decidir o processo. Podemos definir o mediador como um terceiro que deve ser imparcial e deve contribuir para que ocorra a restauração da comunicação entre as partes, cabendo exclusivamente a elas questionar e refletir sobre seus desentendimentos. Para ser mediador é necessário que ele tenha uma capacidade específica para isso, e é recomendado que o mediador tenha formação em direito com no mínimo 3 anos de atividade jurídica, porém o mesmo deve se ater a não fazer uso de termos como "inocente ou culpado" ele deve buscar um fim aonde ambas as partes "ganhem".

Para a vítima, devido ao seu envolvimento direto em todo o processo da mediação, ela consegue expor tanto para o infrator quanto para a sociedade qual o impacto que a mesma sofreu em relação ao conflito, além de conseguir apaziguar a vítima em relação a seu infrator, pois assim ela tem a possibilidade de conhecer os motivos aos quais levou o autor cometer tal ato ilícito, e saber se há realmente um sentimento ou não de arrependimento no autor, logo com a 
participação direta da vítima, a mesma tem a possibilidade de conseguir a reparação do dano, logo a solução do litigio, da forma mais próxima a sua vontade, dando a mesma a sensação de que a justiça fora feita.

Em relação ao infrator, a mediação é uma forma de conscientiza-lo do ato praticado e quais os danos sofridos pela vítima e pela sociedade devido suas ações criminosas, é uma forma de tentar recuperar o mesmo, e incentivá-lo a agir de forma licita, além de reestabelecer a dignidade do indivíduo, lhe poupando de uma condenação penal, que tem muito mais peso em relação a sociedade.

E por fim, para a sociedade, os benefícios trazidos por meio da mediação é que, a mesma, tem a capacidade de apaziguar muitos crimes, e tem maior possibilidade de evitar que o infrator venha ser reincidente, além de fazer o mesmo se sentir mais acolhido pela sociedade, tirando aquela visão de combate ao criminoso, possibilitando a sociedade um sentimento de participar, integrar e dessa forma resolver os problemas criminais por meio de diálogo e não repressão, evitando assim a autotutela.

Com o aumento da população, há também um aumento nos conflitos sociais, logo o poder judiciário acabou entrando em crise, devido ao acúmulo de processos, fazendo a resolução dos mesmos ocorrerem de forma mais vagarosa, tornando então questionável a eficácia do sistema judiciário como a principal fonte da resolução da lide.

O processo é formal, e acaba gerando custos para ambas as partes, pois as mesmas devem arcar com as custas processuais, honorários advocatícios legais e contratuais, além disso, o processo acaba tendo uma longa duração devido ao acumulo de processos, o que acaba gerando uma burocracia além do conflito nem sempre ser solucionado de forma satisfatória em primeira instância, logo acabam ocorrendo diversos recursos, o que aumenta ainda mais a lentidão processual. Deve se focar também, que mesmo após o termino do conflito continuem as lides geradas por meio desse processo entre as partes, devido a atuação do juiz ser aplicar a vontade pura e simples da lei.

Dentre a justiça restaurativa são encontradas inúmeras dificuldades para encontrar um modelo adequado a justiça brasileira, é um grande desafio de fato.

Podemos sintetizar a justiça restaurativa como um método de resolução de conflitos, sendo assim possui princípios divergentes dos propostos pelo modelo tradicional (baseado no processo penal), dessa forma, propõe a participação da vítima e acometedor na resolução do conflito presente, a reparação do dano decorrente do delito e a responsabilização do ofensor de maneira que não condene, e ao mesmo tempo não exclua o ato.

Em razão da utilização de práticas de resolução de conflitos embasadas no diálogo presente entre as pessoas referidas no delito, busca-se alcançar um acordo dentre as partes da relação sob à ofensa e o dano causado à vítima, podemos afirmar ainda, que este modelo é um método com objetivo de reduzir a aplicação de penas, principalmente as penas privativas de liberdades.

As primeiras experiências foram aplicadas no Canadá(1974), Estados Unidos da América(1978), Noruega(1981) e Nova Zelândia(1989). Dentre essas a Noruega e da Nova Zelândia desenvolveram no contexto da justiça juvenil, sendo que apenas está última utilizou a conferência de família como prática restaurativa, as demais experiências utilizaram a mediação vítima-ofensor, e eram voltadas para casos envolvendo adultos ofensores.

Com passar das décadas, à mediação vítima-ofensor foram sendo agregados outras práticas, a exemplo das conferências e dos círculos restaurativos, sendo assim pode se dizer que na década de 1970 a justiça restaurativa se encontrava em uma fase de experimental. 
$\mathrm{Na}$ década de 1980, tais experiências foram institucionalizadas, e dessa forma outros contextos surgiram. Em 1990, finalmente a justiça restaurativa se expandiu, e assim se articulou de forma mais profunda no sistema de justiça criminal, de forma que passou a ser inserida em todas as etapas do processo penal.

No Brasil, as primeiras experiências com justiça restaurativa foram implantadas somente em 2005, através do projeto "Promovendo Práticas Restaurativas no Sistema de Justiça Brasileiro", organizado e financiado pelo Ministério da Justiça. Foram três projetos-piloto, um em Porto Alegre/RS, outro em São Caetano do Sul/SP e outro em Brasília/DF. Sendo que os dois primeiros utilizam a prática do círculo restaurativo e se desenvolvem no âmbito da justiça juvenil, enquanto o último utiliza a mediação penal e é aplicado para casos de menor potencial ofensivo envolvendo ofensores adultos, contudo muitos confundem a justiça restaurativa no Brasil como um círculo aplicado apenas como um modelo adequado para crianças e adolescentes em conflito com a lei, porém podemos perceber que os adultos também podem ser inseridos a esse método.

Podemos afirmar que a justiça restaurativa é mais restrita que a mediação porque se aplica somente à esfera criminal, enquanto a mediação é utilizada em conflitos criminais e de outras esferas. A justiça restaurativa se encontra mais ampla em relação às possíveis respostas que o ofensor pode dar. A mediação refere-se apenas às relações entre vítima e ofensor que são estabelecidas na mediação.

\section{CONCLUSÃO}

Por meio desse trabalho, notamos a importância da presença da Mediação no meio processual penal, pois o mesma possibilita a reinserção do infrator na sociedade, sem seja visto como um criminoso, sendo assim acaba evitando que sofra uma condenação penal, além de envolver a vítima durante todo o processo, permitindo que o indivíduo, possa ter uma visão diferente do infrator podendo perdoa-lo, dessa forma ajudando a conscientizar o mesmo, evitando reincidências futuras.

Infelizmente, a mediação acaba por não agradar à todos, por ser um modelo novo e diferenciado, há quem diga que o método não é eficaz, porém não se torna majoritário, pois diante da crise carcerária que o país está enfrentando, a mediação é a melhor forma de amenizar toda a lotação no sistema, deixando-o apenas para crimes mais graves.

Diante do exposto, podemos concluir que, o ideal é que haja um maior incentivo da mediação dentro do âmbito penal, pois tal sistema é mais eficaz na resolução de conflitos menores, e a única prática restaurativa que é especificada, além de evitar em grande parte que haja a reincidência; e o principal a persecução penal é mais palpável, célere, e menos custosa tanto para o Estado, como para a sociedade, sendo assim, isso indica que é o momento de implementar novas experiências na justiça restaurativa, pois a mediação já se passou de fase experimental no âmbito não-criminal.

\section{REFERÊNCIAS BIBLIOGRÁFICAS}

> https://www.priberam.pt/dlpo/conflito < Acesso em 13/08/2017

> https://www.dicio.com.br/mediador/< Acesso em 13/08/2017

>https://jus.com.br/artigos/56830/o-sistema-de-mediacao-no-atual-direito-processual-penalbrasileiro/1< Acesso em 10/08/2017 
>https://canalcienciascriminais.com.br/justica-restaurativa-e-mediacao-penal-afinal-qual-arelacao-entre-elas-2/ < acesso 13/08/2017.

CAMPANÁRIO. Micaela Susana Nóbrega. Mediação Penal: Inserção dos meios de solução de conflitos. Civitas, Porto Alegre, v. 13, n. 1, p. 118-135, jan.-abr,2013.

https://jus.com.br/artigos/57992/mediacao-penal-uma-via-de-acesso-a-justica-criminalhumanizada/2 < acesso 14/08/2017 